\title{
Solid-State Structural Properties of Alloxazine Determined from Powder XRD Data in Conjunction with DFT-D Calculations and Solid- State NMR Spectroscopy: Unraveling the Tautomeric Identity and Pathways for Tautomeric Interconversion
}

\author{
Christopher J. H. Smalley, Andrew J. Logsdail, Colan E. Hughes, Dinu Iuga, Mark T. Young, \\ and Kenneth D. M. Harris*
}

Cite This: Cryst. Growth Des. 2022, 22, 524-534

Read Online

ACCESS

Wll Metrics \& More

Article Recommendations

Supporting Information

ABSTRACT: We report the solid-state structural properties of alloxazine, a tricyclic ring system found in many biologically important molecules, with structure determination carried out directly from powder X-ray diffraction (XRD) data. As the crystal structures containing the alloxazine and isoalloxazine tautomers both give a high-quality fit to the powder XRD data in Rietveld refinement, other techniques are required to establish the tautomeric form in the solid state. In particular, high-resolution solid-state ${ }^{15} \mathrm{~N}$ NMR data support the presence of the alloxazine tautomer, based on comparison between isotropic chemical shifts

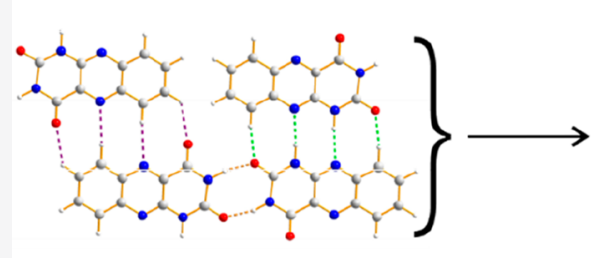

Structure from Powder XRD. Solid-State NMR and DFT-D

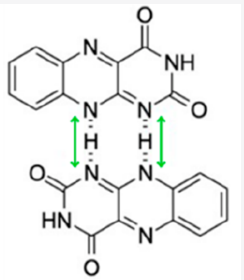

Tautomeric Interconversion Mechanism (DFT-D) in the experimental ${ }^{15} \mathrm{~N}$ NMR spectrum and the corresponding values calculated for the crystal structures containing the alloxazine and isoalloxazine tautomers. Furthermore, periodic DFT-D calculations at the PBE0-MBD level indicate that the crystal structure containing the alloxazine tautomer has significantly lower energy. We also report computational investigations of the interconversion between the tautomeric forms in the crystal structure via proton transfer along two intermolecular $\mathrm{N}-\mathrm{H} \cdots \mathrm{N}$ hydrogen bonds; DFT-D calculations at the PBE0-MBD level indicate that the tautomeric interconversion is associated with a lower energy transition state for a mechanism involving concerted (rather than sequential) proton transfer along the two hydrogen bonds. However, based on the relative energies of the crystal structures containing the alloxazine and isoalloxazine tautomers, it is estimated that under conditions of thermal equilibrium at ambient temperature, more than $99.9 \%$ of the molecules in the crystal structure will exist as the alloxazine tautomer.

\section{INTRODUCTION}

The heterocyclic alloxazine/isoalloxazine ring system is found in many biologically important molecules. For example, it is present in all flavins, such as riboflavin, flavin mononucleotide (FMN), and flavin adenine dinucleotide (FAD); both FMN and $\mathrm{FAD}$ are crucial coenzymes for redox processes in a wide range of biological systems. ${ }^{1}$ The alloxazine molecule (Figure 1) may exist in two tautomeric forms, referred to as alloxazine and isoalloxazine, which differ in the position of one hydrogen atom. Recently, alloxazine has been shown to have potential in<smiles>O=c1[nH]c(=O)c2nc3ccccc3nc2[nH]1</smiles>

Alloxazine<smiles>O=c1nc2[nH]c3ccccc3nc-2c(=O)[nH]1</smiles>

Isoalloxazine battery technology as an energy storage material, with functionalization of alloxazine by electron-donating groups leading to improved performance in this application. ${ }^{2}$ To date, the structural properties of alloxazine in the solid state have not been reported; clearly, knowledge of the crystal structure of alloxazine and the preferred modes of intermolecular interactions may yield important insights in understanding the structural chemistry of flavins in different environments.

Although single-crystal X-ray diffraction (XRD) is the most powerful and routine method for crystal structure determination, this technique relies on the availability of a singlecrystal specimen of suitable size and quality. When a suitable single crystal cannot be prepared, it is necessary instead to use

Received: September 25, 2021

Revised: October 25, 2021

Published: November 22, 2021

Figure 1. Molecular structures of alloxazine (left) and isoalloxazine (right). 
powder XRD data for structure determination. Although structure determination from powder XRD data is more challenging than from single-crystal XRD data, modern methodology ${ }^{3-11}$ allows crystal structures of organic materials of moderate complexity to be determined directly from powder XRD data, particularly by exploiting the direct-space strategy for structure solution and the Rietveld method for structure refinement. Furthermore, the process of structure determination from powder XRD data may be enhanced ${ }^{12-18}$ by taking advantage of insights gained from complementary experimental techniques (e.g., solid-state NMR spectroscopy) and computational techniques (e.g., periodic DFT-D calculations).

Herein, we report the solid-state structural properties of alloxazine, determined from powder XRD data in conjunction with insights derived from solid-state NMR spectroscopy and DFT-D calculations, which provide important independent evidence allowing the assignment of the tautomeric form (alloxazine versus isoalloxazine) that exists in the crystal structure. Energetic and mechanistic aspects of pathways for interconversion between the alloxazine and isoalloxazine tautomers in the crystal structure are also explored using computational approaches.

\section{STRUCTURE DETERMINATION FROM POWDER XRD DATA}

High-quality powder XRD data were recorded for a sample of alloxazine crystallized from DMSO (see Methods for details). The powder XRD data were indexed using the program LZON $^{19}$ in the CRYSFIRE package, ${ }^{20}$ giving the following unit cell with triclinic metric symmetry: $a=5.86 \AA, b=7.61 \AA, c=$ $10.16 \AA, \alpha=69.9^{\circ}, \beta=83.5^{\circ}, \gamma=83.1^{\circ}\left(V=421.2 \AA^{3}\right)$. Unit cell and profile refinement were carried out using the Le Bail method $^{21}$ in the GSAS program package, ${ }^{22}$ giving a good quality of fit to the experimental powder XRD data (Figure 2; $\left.R_{\text {wp }}=1.07 \%, R_{\mathrm{p}}=0.80 \%\right)$. Knowledge of the unit cell volume and consideration of density suggest that the unit cell contains two molecules of alloxazine. Thus, the asymmetric unit would comprise one molecule $\left(Z^{\prime}=1\right)$ for space group $P \overline{1}$ or two molecules $\left(Z^{\prime}=2\right)$ for space group $P 1$.

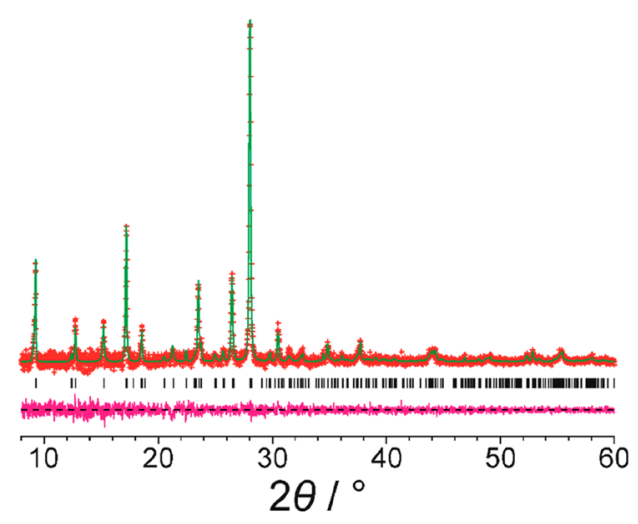

Figure 2. Profile fitting (using the Le Bail method) of the powder XRD data (background subtracted) recorded for alloxazine, showing the experimental powder XRD data (red “+” marks), the calculated powder XRD data (green line), the predicted peak positions (black tick marks), and the difference between experimental and calculated powder XRD data (magenta line).
Structure solution was carried out using the direct-space genetic algorithm (GA) technique incorporated in the program EAGER, ${ }^{23-26}$ which has been applied to solve the crystal structures of materials from a range of areas of application, including materials of biological relevance, ${ }^{27-29}$ framework structures, ${ }^{30,31}$ products from solid-state reactions, ${ }^{32,33}$ optoelectronic materials, ${ }^{34,35}$ multicomponent organic materials, ${ }^{36,37}$ and polymorphic systems. ${ }^{38}$ Structure solution was carried out initially for space group $P \overline{1}\left(Z^{\prime}=1\right)$, using a molecular model for alloxazine constructed with standard bond lengths and bond angles from the Cambridge Structural Database using the MOGUL program ${ }^{39}$ and with bond lengths involving hydrogen atoms taken from Allen et al. ${ }^{40}$ As there is one molecule of alloxazine in the asymmetric unit for space group $P \overline{1}$, each trial structure (using the alloxazine tautomer) was defined by six structural variables (three positional and three orientational variables). In total, 40 independent GA structure-solution calculations were carried out, each starting from a different randomly generated initial population. Each GA calculation involved the evolution of a population of 100 trial structures for 100 generations, with 10 mating operations and 50 mutation operations per generation. All 40 independent calculations produced the same trial structure giving the best fit to the experimental powder XRD data (i.e., lowest $R_{\mathrm{wp}}$ ). This structure was considered reasonable on the basis of structural and chemical criteria and was used as the starting structural model for Rietveld refinement.

Structure solution was also carried out for space group $P 1$ with $Z^{\prime}=2$. In this case, each trial structure was defined by nine variables (three positional variables and six orientational variables; for space group $P 1$, the position of one molecule in the unit cell can be fixed arbitrarily). The trial structure giving the best fit to the experimental powder XRD data was essentially identical to the structure obtained for space group $P \overline{1}$, confirming that the description of the structure in space group $P \overline{1}$ is correct.

The best trial structure obtained in the GA structure solution calculations for space group $P \overline{1}$ was used as the initial structural model for Rietveld refinement, ${ }^{41}$ which was carried out using the GSAS program. ${ }^{22}$ In the Rietveld refinement, standard restraints were applied to bond lengths and bond angles, and planar restraints were applied to the tricyclic ring system. A common isotropic displacement parameter was refined for all non-hydrogen atoms, with the value for hydrogen atoms set to 1.2 times the refined value for the non-hydrogen atoms. No corrections for preferred orientation were applied. $^{42}$ The Rietveld refinement gave an excellent fit to the experimental powder XRD data (Figure 3; $R_{\mathrm{wp}}=1.15 \%, R_{\mathrm{p}}$ $=0.86 \%$ ), comparable to the quality of fit obtained in the Le Bail profile fitting (Figure 2), with the following final refined unit cell parameters: $a=5.8638(6) \AA, b=7.6066(6) \AA, c=$ 10.1644(9) $\AA, \alpha=69.972(7)^{\circ}, \beta=83.493(8)^{\circ}, \gamma=$ 83.061(6) $)^{\circ}, V=421.57(9) \AA^{3}$. The crystal structure from this Rietveld refinement is deposited in the CSD (deposition number: 2111430) and in the Supporting Information.

For structure validation, the final refined crystal structure was subjected to geometry optimization (with fixed unit cell) using periodic DFT-D calculations. The geometry optimized structure shows only minor differences in atomic positions compared to the structure obtained in the Rietveld refinement [with root-mean squared deviation (RMSD) in the positions of the non-hydrogen atoms of $0.082 \AA]$, confirming that the final refined crystal structure is close to a minimum on the energy 


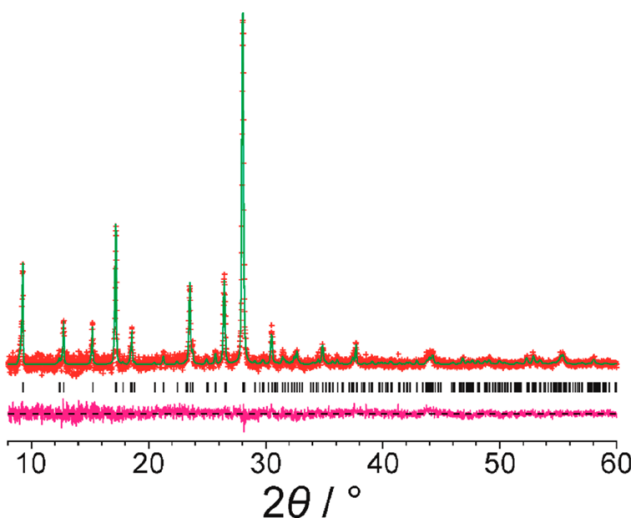

Figure 3. Final Rietveld refinement of the powder XRD data (background subtracted) recorded for alloxazine, showing the experimental powder XRD data (red " + " marks), the calculated powder XRD data (green line), the predicted peak positions (black tick marks), and the difference between experimental and calculated powder XRD data (magenta line).

landscape. The crystal structure from the final Rietveld refinement and the structure obtained after subjecting this structure to DFT-D geometry optimization are compared in Figure S1.

\section{RESULTS AND DISCUSSION}

Crystal Structure of Alloxazine. The crystal structure of alloxazine comprises layers (Figure 4) of molecules connected by three different hydrogen-bonding motifs between a given molecule and three neighboring molecules. Figure 5 shows the intermolecular interactions between a reference molecule, labeled $A$, and three neighboring molecules within the layer, labeled B, C, and D. The hydrogen bonding to one neighbor (the A-B interaction motif, indicated by green dashed lines in Figures 4 and 5) is a self-complementary motif involving two $\mathrm{N}-\mathrm{H} \cdots \mathrm{N}$ interactions $[\mathrm{N} \cdots \mathrm{N}, 3.110(3) \AA ; \mathrm{N}-\mathrm{H} \cdots \mathrm{N}$, $\left.173.7(3)^{\circ}\right]$ and two $\mathrm{C}-\mathrm{H} \cdots \mathrm{O}$ interactions [C... $\AA$; $\mathrm{C}-\mathrm{H} \cdots \mathrm{O}, 170.6(3)^{\circ}$. The two molecules involved in this interaction motif are related across an inversion center; thus, the two $\mathrm{N}-\mathrm{H} \cdots \mathrm{N}$ interactions are symmetry equivalent, and

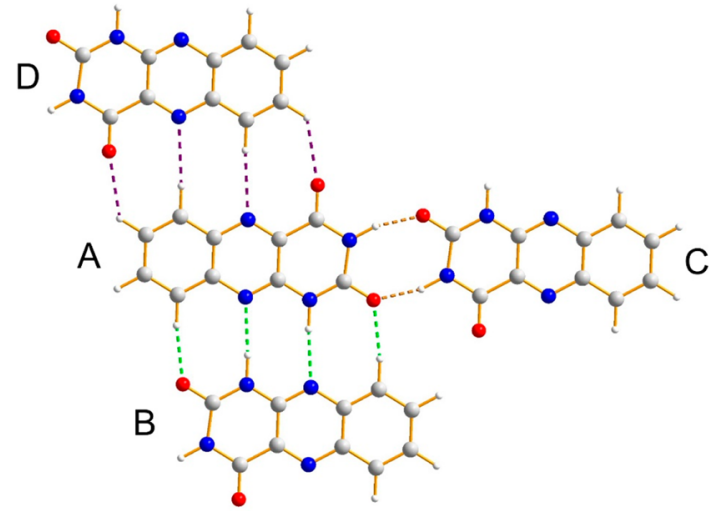

Figure 5. Intermolecular interaction motifs in the crystal structure of alloxazine viewed perpendicular to the molecular planes. Molecules A, $\mathrm{B}$, and $\mathrm{D}$ lie very close to the same plane, whereas molecule $\mathrm{C}$ is slightly offset in the direction perpendicular to this plane. Hydrogen bonds (including $\mathrm{C}-\mathrm{H} \cdots \mathrm{N}$ and $\mathrm{C}-\mathrm{H} \cdots \mathrm{O}$ interactions) are indicated by dashed lines with the following color code: A-B interaction motif, green; A-C interaction motif, gold; A-D interaction motif, purple.

the two $\mathrm{C}-\mathrm{H} \cdots \mathrm{O}$ interactions are symmetry equivalent. The planes of the two molecules are parallel to each other and lie very close to the same plane.

The interaction with another neighboring molecule in the same layer (the A-D interaction motif, indicated by purple dashed lines in Figures 4 and 5) comprises a set of two $\mathrm{C}-\mathrm{H} \cdots \mathrm{O}$ interactions and two $\mathrm{C}-\mathrm{H} \cdots \mathrm{N}$ interactions. The two molecules involved in this interaction motif are very close to coplanar and are related across an inversion center; thus, the two $\mathrm{C}-\mathrm{H} \cdots \mathrm{O}$ interactions are symmetry equivalent, and the two $\mathrm{C}-\mathrm{H} \cdots \mathrm{N}$ interactions are symmetry equivalent. Based on geometric criteria, ${ }^{43-45}$ these $\mathrm{C}-\mathrm{H} \cdots \mathrm{O}$ interactions $[\mathrm{C} \cdots \mathrm{O}$, 3.235(8) $\AA$; $\left.\mathrm{C}-\mathrm{H} \cdots \mathrm{O}, 131.0(7)^{\circ}\right]$ and $\mathrm{C}-\mathrm{H} \cdots \mathrm{N}$ interactions $\left[\mathrm{C} \cdots \mathrm{N}, 3.543(6) \AA ; \mathrm{C}-\mathrm{H} \cdots \mathrm{N}, 173.3(7)^{\circ}\right]$ are on the borderline of being classified as $\mathrm{C}-\mathrm{H} \cdots \mathrm{O}$ and $\mathrm{C}-\mathrm{H} \cdots \mathrm{N}$ "hydrogen bonds". For this reason, this set of two $\mathrm{C}-\mathrm{H} \cdots \mathrm{O}$ interactions and two $\mathrm{C}-\mathrm{H} \cdots \mathrm{N}$ interactions is less significant than the $\mathrm{A}-\mathrm{B}$ interaction motif containing the two strong

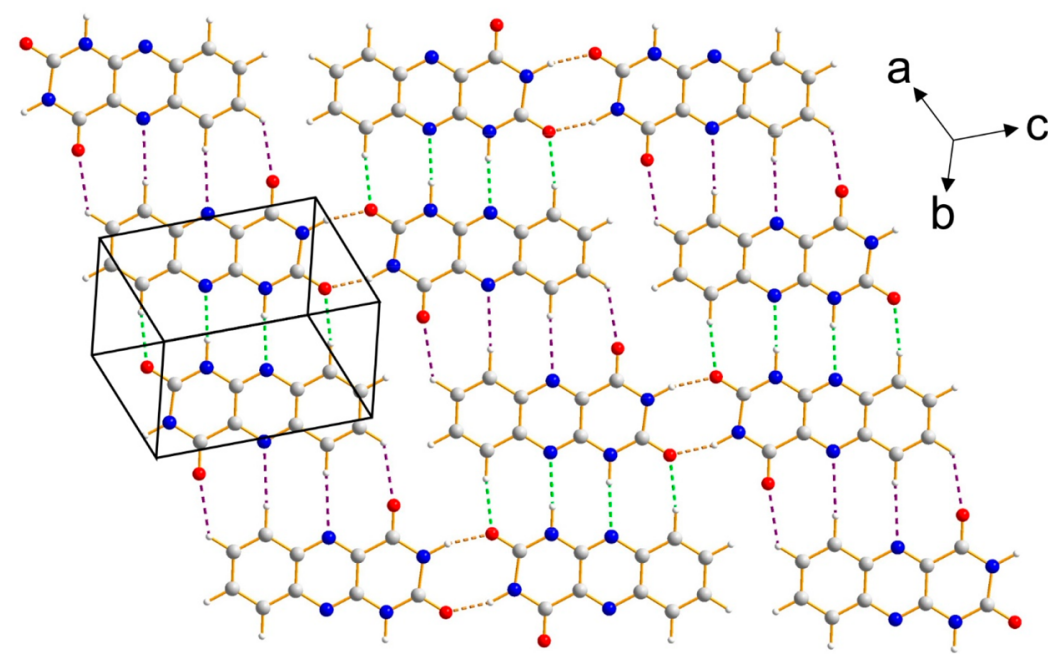

Figure 4. A single hydrogen-bonded layer in the crystal structure of alloxazine viewed perpendicular to the average plane of the layer. Hydrogen bonds (including $\mathrm{C}-\mathrm{H} \cdots \mathrm{N}$ and $\mathrm{C}-\mathrm{H} \cdots \mathrm{O}$ interactions) are indicated by dashed lines with the following color code: A-B interaction motif, green; A$\mathrm{C}$ interaction motif, gold; A-D interaction motif, purple. The A-B, A-C and A-D interaction motifs are defined in Figure 5. 
$\mathrm{N}-\mathrm{H} \cdots \mathrm{N}$ hydrogen bonds discussed above. The combination of the A-B and A-D interaction motifs generates a one-

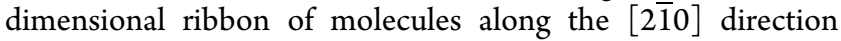
(close to vertical in Figure 4), with all molecules in the ribbon lying very close to the same plane.

The hydrogen bonding to another neighboring molecule (the A-C interaction motif, indicated by gold dashed lines in Figures 4 and 5) is a cyclic array, denoted $R_{2}^{2}(8)$ in graph set notation, ${ }^{46}$ constructed from two $\mathrm{N}-\mathrm{H} \cdots \mathrm{O}$ hydrogen bonds $\left[\mathrm{N} \cdots \mathrm{O}, 2.857(5) \AA ̊ . \mathrm{N}-\mathrm{H} \cdots \mathrm{O}, 147.6(6)^{\circ}\right]$. This interaction motif links adjacent ribbons within the hydrogen-bonded layer. The two molecules in this interaction motif are related across an inversion center; however, while the planes of the two molecules are parallel, they are not coplanar, as the positions of the two molecules are slightly offset along the direction perpendicular to the molecular planes (thus, the inversion center lies midway between the planes of the two molecules). As a consequence, the hydrogen-bonded layers are "step-like" rather than flat (see Figure 6), with each step corresponding to

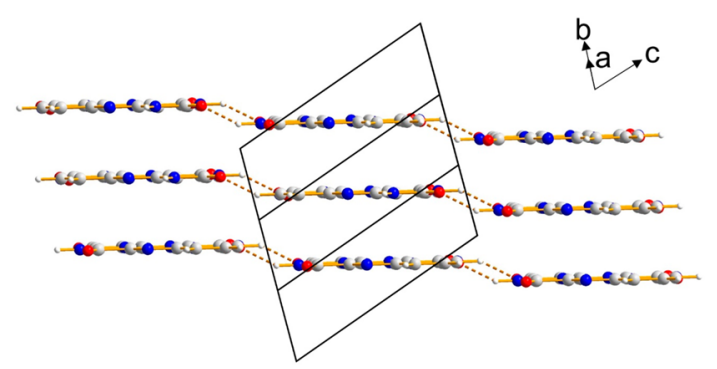

Figure 6. Crystal structure of alloxazine, viewed parallel to the molecular planes, showing three layers of molecules constructed from hydrogen-bonded ribbons. Molecules linked by two $\mathrm{N}-\mathrm{H} \cdots \mathrm{O}$ hydrogen bonds (gold dashed lines) representing the A-C interaction motif (see Figure 5) are not coplanar and are offset slightly in the direction perpendicular to the molecular plane, giving rise to the stepped arrangement shown.

the hydrogen-bonded "interface" (comprising A-C interactions) between adjacent ribbons. In Figure 6, the stacking of adjacent hydrogen-bonded layers is viewed parallel to the molecular plane, clearly showing the step-like character of each layer. The perpendicular distance between adjacent layers [taking the mean plane of the stepped layers as (122)] is 3.17 $\AA$; the perpendicular distance between the mean planes of the molecular ribbons in adjacent layers is $3.26 \AA$.

Finally, we consider the relation between this crystal structure and the crystal structures of derivatives of alloxazine reported previously (CSD Refcodes: CODYEZ10, ${ }^{47}$ FUDWOQ $^{48}{ }^{4}$ FISLID, ${ }^{49}$ AGEPEK $^{50}$ ), focusing only on derivatives that retain all the hydrogen-bond donor and acceptor groups of the alloxazine molecule (and thus involve only substitution of the $\mathrm{C}_{6}$ ring). Among these four structures, all of which are solvates, only the methanol solvate of 7,8-dimethylalloxazine ${ }^{49}$ contains hydrogen-bonding motifs that resemble those in the structure of alloxazine reported here. Specifically, a given molecule of 7,8-dimethylalloxazine is linked to two adjacent molecules by the A-B and A-C interaction motifs, while the other $\mathrm{N}$ acceptor is engaged in an $\mathrm{O}-\mathrm{H} \cdots \mathrm{N}$ hydrogen bond with the $\mathrm{O}-\mathrm{H}$ bond of the methanol molecule (rather than forming the A-D interaction motif observed in the structure of alloxazine). In the other structures, the intermolecular interactions predominantly ${ }^{47,48}$ or entirely ${ }^{50}$ involve hydrogen bonding between the alloxazine derivative and solvent molecules.

Assessment of Alloxazine/lsoalloxazine Tautomerism. As the alloxazine and isoalloxazine tautomers differ only in the position of one hydrogen atom (with only small geometric differences in other parts of the molecule resulting from the different position of this hydrogen atom), the isoalloxazine tautomer should be able to form an essentially identical crystal structure to alloxazine, with the only significant difference being the position of the hydrogen atom within each intermolecular $\mathrm{N}-\mathrm{H} \cdots \mathrm{N}$ hydrogen bond (i.e., $\mathrm{N}-\mathrm{H} \cdots \mathrm{N}$ versus $\mathrm{N} \cdots \mathrm{H}-\mathrm{N}$ ) that links pairs of neighboring molecules (within the A-B interaction motif). Clearly, as the only significant difference between the crystal structures containing the alloxazine and isoalloxazine tautomers would be the position of one hydrogen atom in the asymmetric unit (with only minor structural differences in other aspects of molecular geometry), the powder XRD patterns of the two structures would be virtually indistinguishable.

To explore this issue in more detail, the molecule in the crystal structure of alloxazine was converted to the isoalloxazine tautomer and then subjected to Rietveld refinement using the same experimental powder XRD data set. The Rietveld refinement gave a good fit to the powder XRD data (Figure $7 ; R_{\mathrm{wp}}=1.18 \%, R_{\mathrm{p}}=0.88 \%$ ), very similar in

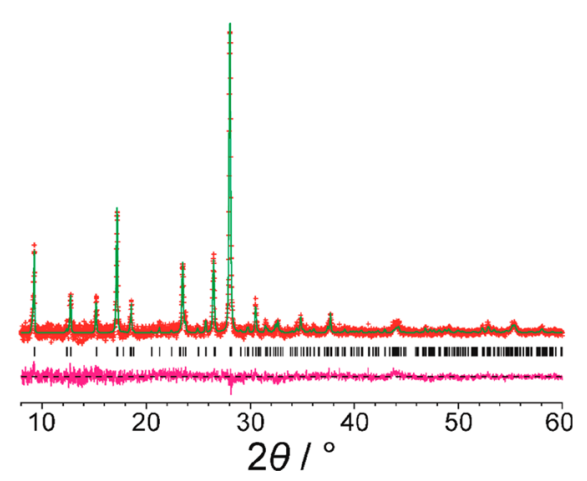

Figure 7. Final Rietveld refinement of the powder XRD data (background subtracted) recorded for alloxazine, using a structural model in which the alloxazine molecule was replaced by the isoalloxazine tautomer. The plot shows the experimental powder XRD data (red "+" marks), the calculated powder XRD data (green line), the predicted peak positions (black tick marks), and the difference between experimental and calculated powder XRD data (magenta line).

quality of fit to the Rietveld refinement using the alloxazine tautomer, although with slightly higher discrepancies between experimental and calculated powder XRD patterns as reflected in the slightly higher values of $R_{\mathrm{wp}}$ and $R_{\mathrm{p}}$. The final refined unit cell parameters $[a=5.8633(7) \AA, b=7.6064(6) \AA, c=$ 10.1637(10) $\AA, \alpha=69.976(7)^{\circ}, \beta=83.497(9)^{\circ}, \gamma=$ $\left.83.063(6)^{\circ}, V=421.51(9) \AA^{3}\right]$ are essentially the same, within the estimated standard deviations (esds) in the refined parameters, as those obtained in the Rietveld refinement for alloxazine using the same powder XRD data set. The crystal structure containing the isoalloxazine tautomer from this Rietveld refinement is deposited in the Supporting Information.

The relative energetic stabilities of the crystal structures containing the alloxazine and isoalloxazine tautomers were assessed from periodic DFT-D calculations. Initially, the crystal 
structure for each tautomer obtained in the final Rietveld refinement was subjected to geometry optimization with fixed unit cell ${ }^{51}$ using the PBE-TS method. In the geometryoptimized crystal structures, the $\mathrm{N}-\mathrm{H} \cdots \mathrm{N}$ hydrogen bond angles are close to linear in each structure $(\mathrm{N}-\mathrm{H} \cdots \mathrm{N}$ : alloxazine, $178.5^{\circ}$; isoalloxazine, $176.4^{\circ}$ ), but the $\mathrm{N}-\mathrm{H} \cdots \mathrm{N}$ hydrogen bond distances are significantly shorter for

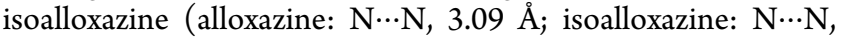
$2.99 \AA$ ). For each geometry-optimized crystal structure, singlepoint energy calculations were carried out using different functionals (PBE and PBE0) combined with different methods for dispersion correction (TS and MBD). For each calculation method, the calculated energy is higher for the isoalloxazine structure than the alloxazine structure, with the following energy differences (expressed per mole of molecules): 17.8 $\mathrm{kJ} \mathrm{mol}^{-1}$ (PBE-TS); $17.2 \mathrm{~kJ} \mathrm{~mol}^{-1}$ (PBE-MBD); $23.8 \mathrm{~kJ} \mathrm{~mol}^{-1}$ (PBE0-TS); $23.3 \mathrm{~kJ} \mathrm{~mol}^{-1}$ (PBE0-MBD). The magnitude of these energy differences suggests that the crystal structure containing the alloxazine tautomer will be strongly favored in the experimental situation. Calculation of the relative Boltzmann factor for the two tautomeric states indicates that, under conditions of thermal equilibrium at $298 \mathrm{~K}$, more than 99.9\% of the molecules in the crystal structure would exist as the alloxazine tautomer. The significant difference in energy between the alloxazine and isoalloxazine crystal structures is dominated by the difference in intramolecular energy between the alloxazine and isoalloxazine tautomers, which favors alloxazine by $54.0 \mathrm{~kJ} \mathrm{~mol}^{-1}$ (PBE0-MBD), rather than differences in the energies of intermolecular interactions within the crystal structures, which favors isoalloxazine by 30.7 $\mathrm{kJ} \mathrm{mol}^{-1}$ (PBE0-MBD). Thus, the intermolecular cohesion is actually weaker in the crystal structure containing the alloxazine tautomer.

To seek direct experimental verification of the tautomeric form present in the crystal structure, high-resolution solid-state ${ }^{15} \mathrm{~N}$ NMR and ${ }^{13} \mathrm{C}$ NMR data were recorded for the same sample of alloxazine used in the powder XRD study.

The high-resolution solid-state ${ }^{15} \mathrm{~N}$ NMR spectrum, shown in Figure 8, contains isotropic peaks at 123.81 and $156.56 \mathrm{ppm}$ (chemical shift difference, $32.75 \mathrm{ppm}$ ). Although there are four distinct ${ }^{15} \mathrm{~N}$ environments in the crystal structure (i.e., four distinct ${ }^{15} \mathrm{~N}$ environments in the alloxazine molecule, with one independent molecule in the asymmetric unit), the conditions

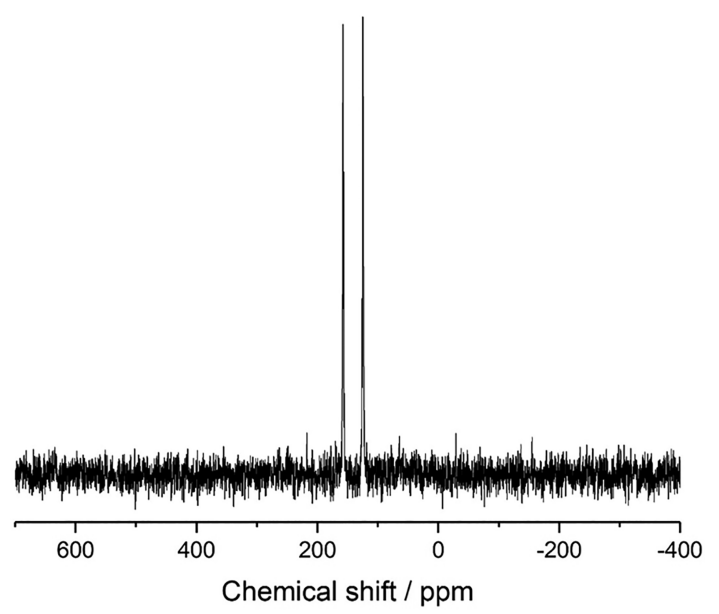

Figure 8. High-resolution solid-state ${ }^{15} \mathrm{~N}$ NMR spectrum recorded for alloxazine. of the measurement of the solid-state ${ }^{15} \mathrm{~N}$ NMR spectrum (involving ${ }^{1} \mathrm{H} \rightarrow{ }^{15} \mathrm{~N}$ cross-polarization with contact time $\tau_{\mathrm{cp}}=$ $2 \mathrm{~ms}$ ) are such that signals of significant intensity are observed only for ${ }^{15} \mathrm{~N}$ nuclei directly bonded to ${ }^{1} \mathrm{H}$ nuclei. Interpretation of the experimental solid-state ${ }^{15} \mathrm{~N}$ NMR spectrum is greatly facilitated by the capability to calculate the isotropic ${ }^{15} \mathrm{~N}$ chemical shifts for the crystal structures of the alloxazine and isoalloxazine tautomers determined from the powder XRD data, giving resonances at 126.68 and $161.43 \mathrm{ppm}$ (chemical shift difference, $34.75 \mathrm{ppm}$ ) for the two $\mathrm{N}-\mathrm{H}$ environments in the alloxazine crystal structure ( $\mathrm{N}$ atoms labeled 2 and 3 in Table 1) and at 149.94 and 165.64 ppm (chemical shift

Table 1. Isotropic ${ }^{15} \mathrm{~N}$ NMR Chemical Shifts Measured from the Experimental Solid-State ${ }^{15} \mathrm{~N}$ NMR Spectrum $\left(\delta_{\text {exp }}\right)$ and Determined from DFT-D Calculations for the Crystal Structures Containing the Alloxazine Tautomer $\left[\delta_{\text {calc }}(\right.$ alloxazine $\left.)\right]$ and the Isoalloxazine Tautomer $\left[\delta_{\text {calc }}(\text { isoalloxazine })\right]^{a}$
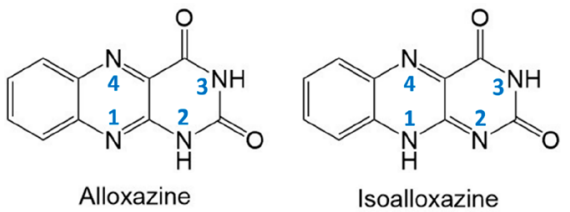

$\begin{array}{cccc}{ }^{15} \mathrm{~N} \text { site } & \delta_{\text {calc }}(\text { alloxazine }) / \mathrm{ppm} & \delta_{\text {exp }} / \mathrm{ppm} & \delta_{\text {calc }}(\text { isoalloxazine }) / \mathrm{ppm} \\ 1 & 255.37 & & 149.94(\mathrm{NH}) \\ 2 & \mathbf{1 2 6 . 6 8 ( \mathrm { NH } )} & 123.81(\mathrm{NH}) & 182.85 \\ 3 & 161.43(\mathrm{NH}) & 156.56(\mathrm{NH}) & \mathbf{1 6 5 . 6 4}(\mathrm{NH}) \\ 4 & 337.01 & & 349.36\end{array}$

${ }^{a_{\text {The }}}$ isotropic ${ }^{15} \mathrm{~N}$ NMR chemical shifts calculated for the $\mathrm{NH}$ environments in each crystal structure are highlighted in bold. The numbering of the ${ }^{15} \mathrm{~N}$ sites in each tautomer is defined in the structures above. Based on comparison between experimental and calculated chemical shifts, the two ${ }^{15} \mathrm{~N}$ NMR resonances observed in the experimental solid-state ${ }^{15} \mathrm{~N}$ NMR spectrum are assigned to the $\mathrm{NH}$ environments in the crystal structure containing the alloxazine tautomer.

difference, $15.70 \mathrm{ppm}$ ) for the two $\mathrm{N}-\mathrm{H}$ environments in the isoalloxazine crystal structure $(\mathrm{N}$ atoms labeled 1 and 3 in Table 1). As shown in Table 1 , the match between the calculated and experimental values of the isotropic ${ }^{15} \mathrm{~N}$ chemical shifts is significantly better for the crystal structure containing alloxazine than the crystal structure containing isoalloxazine. Correspondingly, the chemical shift difference between the two isotropic peaks in the experimental solid-state ${ }^{15} \mathrm{~N}$ NMR spectrum (32.75 ppm) is in significantly better agreement with the difference between the calculated ${ }^{15} \mathrm{~N}$ chemical shifts for the two $\mathrm{N}-\mathrm{H}$ environments in the crystal structure containing alloxazine $(34.75 \mathrm{ppm})$ than the crystal structure containing isoalloxazine $(15.70 \mathrm{ppm})$. These observations give strong support to the conclusion that the material studied in our experimental work contains the alloxazine tautomer rather than the isoalloxazine tautomer.

Consideration of the high-resolution solid-state ${ }^{13} \mathrm{C}$ NMR spectrum, on the other hand, does not provide a definitive assignment of the tautomeric form. The experimental solidstate ${ }^{13} \mathrm{C}$ NMR spectrum contains nine resolved isotropic peaks, which are compared in Figure S2 to the values of the isotropic ${ }^{13} \mathrm{C}$ NMR chemical shifts calculated from DFT-D calculations for the crystal structures containing the alloxazine 


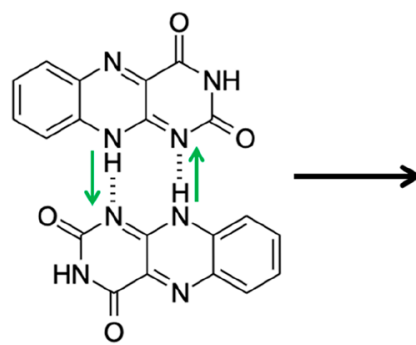

Isoalloxazine

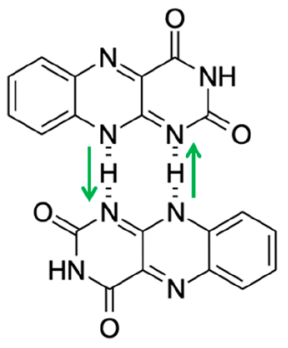

Transition State

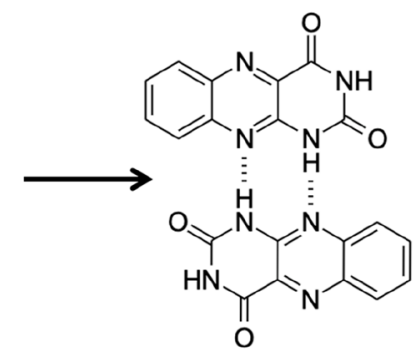

(with symmetric H-bonds)

Figure 9. Schematic of the transformation from the isoalloxazine crystal structure to the alloxazine crystal structure by the concerted mechanism. Green arrows indicate the directions of proton transfer within the $\mathrm{N}-\mathrm{H} \cdots \mathrm{N}$ hydrogen bonds.<smiles></smiles>

Isoalloxazine

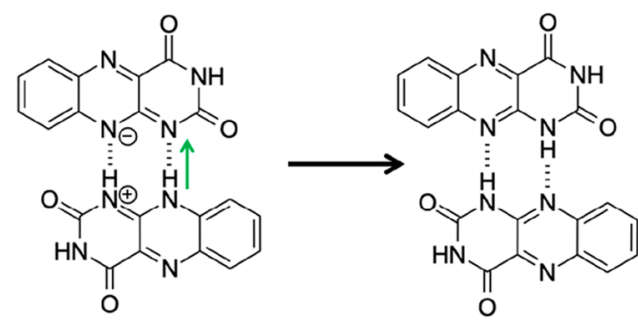

Ionic Intermediate
Alloxazine

Figure 10. Schematic of the transformation from the isoalloxazine crystal structure to the alloxazine crystal structure by the sequential mechanism. Green arrows indicate the directions of proton transfer within the $\mathrm{N}-\mathrm{H} \cdots \mathrm{N}$ hydrogen bonds.

and isoalloxazine tautomers (see also Table S1). Although the overall level of agreement between the experimental and calculated ${ }^{13} \mathrm{C}$ NMR data is somewhat better for the crystal structure containing the alloxazine tautomer, the quality of agreement between the experimental and calculated data is not considered to be sufficiently high to lead to a definitive assignment of the tautomeric form based on these results.

Computational Study of Tautomeric Interconversion in the Crystal Structure of Alloxazine. Another interesting issue relating to the crystal structure of alloxazine concerns the feasibility of interconversion between the alloxazine and isoalloxazine tautomers in the crystal structure, which is considered most likely to occur by proton transfer along the two $\mathrm{N}-\mathrm{H} \cdots \mathrm{N}$ hydrogen bonds that link pairs of neighboring molecules. To explore energetic and mechanistic aspects of this tautomeric interconversion process, transition state calculations were carried out using a nudged elastic band (NEB) method, with the reaction path between the initial and final structures explored using a "chain" of intermediate structures. In the present work, the initial structure was the crystal structure containing the isoalloxazine tautomer, and the final structure was the crystal structure containing the alloxazine tautomer. Each structure within the "chain" of intermediate structures was subjected to periodic DFT-D geometry optimization, while maintaining equal "spacing" to the adjacent structures on the potential energy landscape, which is achieved using a coupling spring constant. A surrogate machine-learned atomistic landscape was used to accelerate convergence (MLNEB), with the efficiency of the transition state search favorably decoupled from the length of the chain representing the reaction path. ${ }^{52}$

By analogy to proton dynamics in similar hydrogen-bonded systems involving double proton transfer processes within a pair of hydrogen bonds (for example, the carboxylic acid dimer ${ }^{53-55}$ ), the interconversion between the alloxazine and isoalloxazine tautomers may be envisaged to proceed via a concerted mechanism in which the protons in the two $\mathrm{N}-\mathrm{H} \cdots \mathrm{N}$ hydrogen bonds linking a pair of adjacent molecules transfer simultaneously (i.e., $\mathrm{N}-\mathrm{H} \cdots \mathrm{N} \leftrightarrow \mathrm{N} \cdots \mathrm{H}-\mathrm{N}$ interconversion) to the other molecule, as shown in Figure 9. This concerted mechanism converts both molecules from one tautomer to the other tautomer via a transition state that contains two essentially symmetrical $\mathrm{N} \cdots \mathrm{H} \cdots \mathrm{N}$ hydrogen bonds.

However, our DFT-D studies of the alloxazine/isoalloxazine system also revealed another pathway involving an ionic intermediate. We refer to this mechanism for tautomeric interconversion as the sequential mechanism, and it is shown schematically in Figure 10. The sequential mechanism involves two steps (described here in the context of the conversion from isoalloxazine to alloxazine). The first step involves proton transfer along only one of the $\mathrm{N}-\mathrm{H} \cdots \mathrm{N}$ hydrogen bonds between a pair of isoalloxazine molecules, leading to the formation of an ionic intermediate containing a protonated cation and a deprotonated anion, which are linked by two $\mathrm{N}-\mathrm{H} \cdots \mathrm{N}$ hydrogen bonds. The second step involves proton transfer along the other $\mathrm{N}-\mathrm{H} \cdots \mathrm{N}$ hydrogen bond, giving rise to two molecules of the alloxazine tautomer. First, we note that DFT-D geometry optimization carried out (using PBE-TS and fixed unit cell) on the ionic intermediate confirms that it is a local energy minimum, representing a metastable structure on the tautomeric transformation pathway [The crystal structures (after DFT-D geometry optimization using PBE-TS) of alloxazine, isoalloxazine, and the ionic intermediate, as used in our studies of interconversion between the alloxazine and isoalloxazine tautomers, are deposited in the Supporting 
Information.]. Following geometry optimization of the ionic intermediate (using the PBE-TS method), the energy of this crystal structure was calculated using different methods. In each case, the energy of the ionic intermediate is higher than the energy of the isoalloxazine crystal structure by $9.2 \mathrm{~kJ} \mathrm{~mol}^{-1}$ (PBE-TS), $8.6 \mathrm{~kJ} \mathrm{~mol}^{-1}$ (PBE-MBD), $9.9 \mathrm{~kJ} \mathrm{~mol}^{-1}$ (PBE0TS), and $9.5 \mathrm{~kJ} \mathrm{~mol}^{-1}$ (PBE0-MBD). The two $\mathrm{N}-\mathrm{H} \cdots \mathrm{N}$ hydrogen bonds linking the anion-cation pair in the ionic intermediate are shorter $(\mathrm{N} \cdots \mathrm{N}, 2.86,2.91 \AA)$ than those linking pairs of molecules in the crystal structures of alloxazine $(\mathrm{N} \cdots \mathrm{N}, 3.09 \AA)$ and isoalloxazine $(\mathrm{N} \cdots \mathrm{N}, 2.99 \AA)$. Clearly, the inversion center that relates the two $\mathrm{N}-\mathrm{H} \cdots \mathrm{N}$ hydrogen bonds in the crystal structures containing the isoalloxazine and alloxazine tautomers (which have $P \overline{1}$ space group symmetry) is lost in forming the ionic intermediate, which has $P 1$ space group symmetry.

For the calculations using the PBE-TS exchange-correlation functional (Figure 11a), the energy barrier for conversion of the isoalloxazine crystal structure to the alloxazine crystal structure by the concerted mechanism is $21.6 \mathrm{~kJ} \mathrm{~mol}^{-1}$, while the sequential mechanism has a lower energy barrier of 17.0
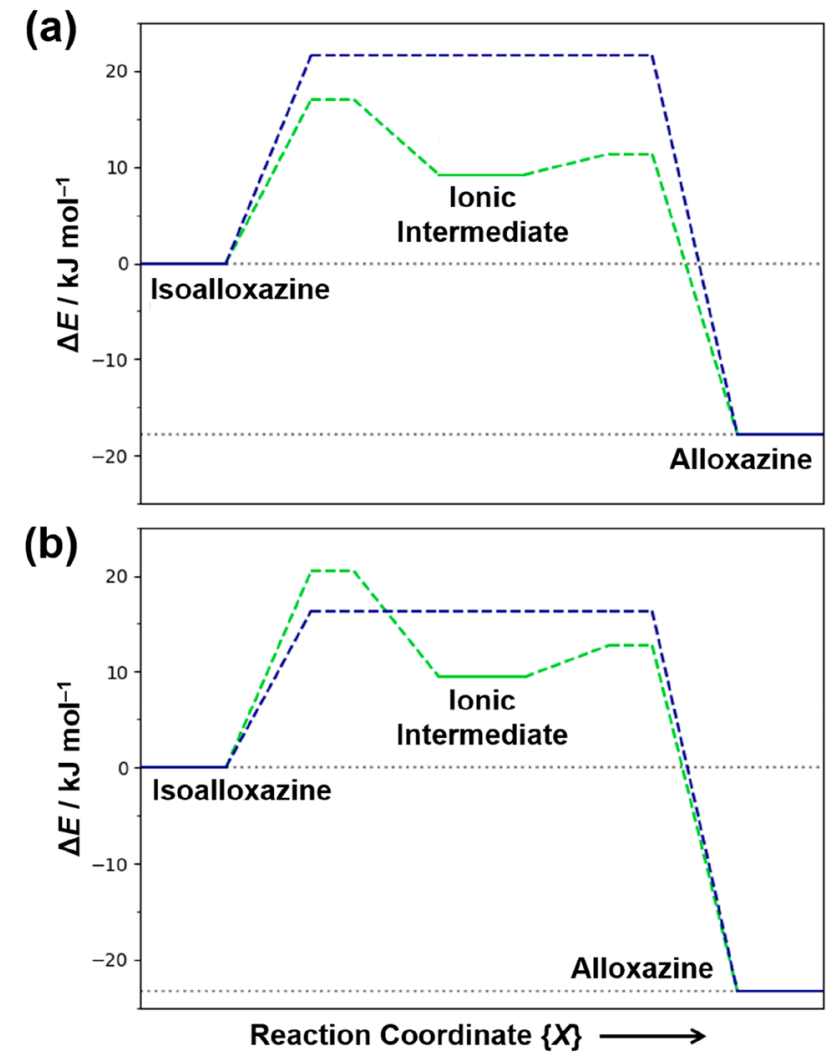

Figure 11. Energy profiles for tautomeric interconversion by the concerted mechanism (blue) and the sequential mechanism (green) calculated using (a) PBE-TS and (b) PBE0-MBD. In each case, the horizontal axis represents the general reaction coordinate, and the vertical axis shows the energy relative to the crystal structure containing the isoalloxazine tautomer. Solid lines indicate stable/ metastable structures, dashed lines indicate transition processes (with horizontal dashed lines representing transition states), and gray dotted lines indicate the energy levels for the crystal structures containing the alloxazine and isoalloxazine tautomers. For the energy profiles calculated using PBE0-MBD, the concerted mechanism is more favorable. For the energy profiles calculated using PBE-TS, the sequential mechanism is more favorable.
$\mathrm{kJ} \mathrm{mol}^{-1}$ to convert the isoalloxazine crystal structure to the ionic intermediate and $2.2 \mathrm{~kJ} \mathrm{~mol}^{-1}$ to convert the ionic intermediate to the alloxazine crystal structure. The corresponding calculations using the PBE-MBD and PBE0-TS methods also suggest that the highest energy barrier for the sequential mechanism (PBE-MBD, $15.8 \mathrm{~kJ} \mathrm{~mol}^{-1}$; PBE0-TS, $21.5 \mathrm{~kJ} \mathrm{~mol}^{-1}$ ), representing the barrier to convert the isoalloxazine crystal structure to the ionic intermediate, is lower than the energy barrier for the concerted mechanism (PBE-MBD, $20.0 \mathrm{~kJ} \mathrm{~mol}^{-1}$; PBE0-TS, $28.4 \mathrm{~kJ} \mathrm{~mol}^{-1}$ ). In contrast, however, the calculations using the PBE0-MBD exchange-correlation functional (Figure 11b) give a higher energy barrier for the sequential mechanism $\left(20.5 \mathrm{~kJ} \mathrm{~mol}^{-1}\right)$ than the concerted mechanism $\left(16.3 \mathrm{~kJ} \mathrm{~mol}^{-1}\right)$, indicating that the concerted mechanism is now the favored pathway for the tautomeric transformation at this level of DFT-D computation.

Considering the individual contributions to the total energy for each calculation method shows that, for PBE0-MBD, the transition state in the concerted mechanism is particularly stabilized relative to the crystal structures containing the alloxazine and isoalloxazine tautomers (by 24.1 and 23.1 $\mathrm{kJ} \mathrm{mol}^{-1}$, respectively) as a result of the many-body dispersion corrections. $^{56}$ In the transition state for the concerted mechanism, the hydrogen atom in each $\mathrm{N}-\mathrm{H} \cdots \mathrm{N}$ hydrogen bond is essentially equidistant between the two nitrogen atoms, and these $\mathrm{N}-\mathrm{H} \cdots \mathrm{N}$ hydrogen bonds are considerably shorter $(\mathrm{N} \cdots \mathrm{N}, 2.69 \AA)$ than those in the crystal structures of the alloxazine tautomer, the isoalloxazine tautomer, and the ionic intermediate in the sequential mechanism $(\mathrm{N} \cdots \mathrm{N}$ in the range 2.86-3.09 $\AA$; the specific values are discussed above). These shorter $\mathrm{N}-\mathrm{H} \cdots \mathrm{N}$ hydrogen bonds may facilitate the stabilization of the transition state when the many-body dispersion correction is implemented and may explain the lower overall energy barrier calculated using PBE0-MBD. These observations highlight the importance of considering high-level dispersion corrections in future investigations of other proton transfer processes in hydrogen bonds. We note that, among these methods, PBE0-MBD is considered ${ }^{57,58}$ to give the most reliable assessment of the energetic properties of organic materials.

\section{CONCLUDING REMARKS}

The crystal structure of alloxazine has been determined directly from powder XRD data, augmented by information from solidstate NMR data and periodic DFT-D calculations. However, the powder XRD data alone cannot definitively establish the tautomeric form present in the crystal structure, as the only significant difference between the crystal structures containing the alloxazine and isoalloxazine tautomers concerns the position of one hydrogen atom in the asymmetric unit (corresponding to the hydrogen atom in each intermolecular $\mathrm{N}-\mathrm{H} \cdots \mathrm{N}$ hydrogen bond). To resolve this issue, further analysis based on periodic DFT-D calculations and solid-state ${ }^{15} \mathrm{~N}$ NMR spectroscopy strongly support the conclusion that the crystal structure that exists in the experimental situation comprises essentially only the alloxazine tautomer, with no significant population of the isoalloxazine tautomer. These results and conclusions demonstrate the advantages of incorporating insights from spectroscopic data and computational techniques within the protocols for crystal structure determination from powder XRD data.

Computational investigations of the interconversion between the two tautomeric forms of the crystal structure suggest 
that the sequential mechanism (involving a metastable ionic intermediate) is favored based on periodic DFT-D calculations at the PBE-TS, PBE-MBD, and PBE0-TS levels, whereas the concerted mechanism (involving simultaneous transfer of protons in two $\mathrm{N}-\mathrm{H} \cdots \mathrm{N}$ hydrogen bonds between pairs of molecules) is favored based on periodic DFT-D calculations at the PBE0-MBD level. Given that the PBE0-MBD method is widely accepted as giving the most reliable assessment of the energetic properties of organic materials, this observation has wider implications concerning the importance of using highlevel dispersion corrections in computational studies of structural transformations in crystalline solids based on mechanisms involving proton transfer.

\section{METHODS}

Sample Preparation. Alloxazine was purchased from SigmaAldrich as a fine, yellow powder. The material was recrystallized by cooling a solution of alloxazine in DMSO from $130{ }^{\circ} \mathrm{C}$ to ambient temperature. The powder XRD patterns of the directly purchased material and the recrystallized material were identical, representing the same solid phase of alloxazine. No other crystallization solvents or crystallization methods were investigated.

Powder XRD. To record high-quality powder XRD data for structure determination, a sample of the recrystallized material was lightly ground in a mortar and pestle and then loaded into a $0.7 \mathrm{~mm}$ glass capillary, which was flame-sealed. The powder XRD data were recorded at $21{ }^{\circ} \mathrm{C}$ on a Bruker D8 diffractometer operating in transmission mode using Ge-monochromated $\mathrm{CuK} \alpha \alpha_{1}$ radiation $(2 \theta$ range, $4^{\circ}-70^{\circ}$; step size, $0.016^{\circ}$; data collection time, $15.5 \mathrm{~h}$ ).

Solid-State NMR Spectroscopy. High-resolution solid-state ${ }^{13} \mathrm{C}$ NMR data were recorded on a Bruker AVANCE III HD spectrometer (magnetic field, 9.4 T; ${ }^{13} \mathrm{C}$ Larmor frequency, $100.64 \mathrm{MHz}$ ), with the powder sample packed in a zirconia solid-state NMR rotor. The ${ }^{13} \mathrm{C}$ NMR spectrum was recorded at ambient temperature using ramped ${ }^{1} \mathrm{H} \rightarrow{ }^{13} \mathrm{C}$ cross-polarization (CP), magic-angle spinning (MAS spinning frequency, $10 \mathrm{kHz}$ ), and ${ }^{1} \mathrm{H}$ decoupling using the SPINAL64 sequence. ${ }^{59}$ The ${ }^{13} \mathrm{C}$ NMR spectrum was referenced ${ }^{60}$ against the $\alpha$ polymorph of glycine, with the carboxylate resonance set to 176.5 ppm.

High-resolution solid-state ${ }^{15} \mathrm{~N}$ NMR data were recorded at $20.0 \mathrm{~T}$ on a Bruker AVANCE III spectrometer at the U.K. High-Field (850 $\mathrm{MHz})$ Solid-State NMR Facility $\left({ }^{15} \mathrm{~N}\right.$ Larmor frequency, $86.16 \mathrm{MHz}$; ${ }^{1} \mathrm{H}$ Larmor frequency, $850.24 \mathrm{MHz}$ ) with a $4 \mathrm{~mm}$ HY MAS probe (MAS frequency, $8 \mathrm{kHz}$ ) using ramped ${ }^{1} \mathrm{H} \rightarrow{ }^{15} \mathrm{~N}$ cross-polarization (CP contact time, $2 \mathrm{~ms}$ ). The ${ }^{15} \mathrm{~N}$ NMR spectrum was referenced ${ }^{61}$ using the isotropic ${ }^{15} \mathrm{~N}$ NMR chemical shift for the $\delta-{ }^{15} \mathrm{~N}$ site in histidine hydrochloride monohydrate at $\delta=189.5 \mathrm{ppm}$.

Periodic DFT-D Calculations. Periodic DFT-D calculations were carried out at various stages of this work. In conjunction with validation of the crystal structure determined from powder XRD data, periodic DFT-D geometry optimization was carried out (with fixed unit cell) using CASTEP $^{62}$ (Academic Release version 8.0). The calculations used ultrasoft pseudopotentials, ${ }^{63} \mathrm{PBE}$ functional, ${ }^{64}$ semiempirical dispersion corrections using the TS correction scheme, ${ }^{65}$ preserved space group symmetry, periodic boundary conditions, a basis set cutoff energy of $700 \mathrm{eV}$, and a MonkhorstPack grid $^{66}$ of minimum sample spacing $(0.05 \times 2 \pi) \AA^{-1}$. The convergence criteria for geometry optimization were $0.01 \mathrm{eV} \AA^{-1}$ for atomic forces, $0.00001 \mathrm{eV}$ per atom in the total energy, and $0.001 \AA$ for atomic displacements.

Solid-state NMR chemical shifts were calculated using CASTEP (Academic Release version 8.0) for the crystal structures containing the alloxazine and isoalloxazine tautomers determined from powder XRD data, followed by DFT-D geometry optimization (with fixed unit cell) as described above. The Gauge Including Projector Augmented Wave (GIPAW) approach ${ }^{67-72}$ was used with a cutoff energy of $700 \mathrm{eV}$ and PBE functional. For each of the crystal structures containing the alloxazine and isoalloxazine tautomers, a set of isotropic ${ }^{13} \mathrm{C}$ NMR shielding values and a set of isotropic ${ }^{15} \mathrm{~N}$ NMR shielding values were generated from the CASTEP calculations.

From the isotropic ${ }^{13} \mathrm{C}$ NMR shielding value $\left(\sigma_{\text {calc }}\right)$ calculated for each ${ }^{13} \mathrm{C}$ environment in the crystal structure, the corresponding calculated isotropic ${ }^{13} \mathrm{C}$ NMR chemical shift $\left(\delta_{\text {calc }}\right)$ was determined ${ }^{69}$ from the equation $\delta_{\text {calc }}=\left\langle\delta_{\text {exp }}\right\rangle+\left\langle\sigma_{\text {calc }}\right\rangle-\sigma_{\text {calc }}$ where $\left\langle\delta_{\text {exp }}\right\rangle$ denotes the mean of the isotropic ${ }^{13} \mathrm{C}$ NMR chemical shifts determined from the experimental high-resolution solid-state ${ }^{13} \mathrm{C}$ NMR spectrum $\left(\left\langle\delta_{\text {exp }}\right\rangle=140.45 \mathrm{ppm}\right)$ and $\left\langle\sigma_{\text {calc }}\right\rangle$ denotes the mean of the calculated isotropic ${ }^{13} \mathrm{C}$ NMR shielding values $\left(\left\langle\sigma_{\text {calc }}\right\rangle=30.18 \mathrm{ppm}\right.$ for alloxazine; $\left\langle\sigma_{\text {calc }}\right\rangle=30.71 \mathrm{ppm}$ for isoalloxazine $)$.

From the isotropic ${ }^{15} \mathrm{~N}$ NMR shielding value $\left(\sigma_{\text {calc }}\right)$ calculated for each ${ }^{15} \mathrm{~N}$ environment in the crystal structure, the corresponding calculated isotropic ${ }^{15} \mathrm{~N}$ NMR chemical shift $\left(\delta_{\text {calc }}\right)$ was determined from the equation $\delta_{\text {calc }}=\delta_{\text {exp }}($ ref $)+\sigma_{\text {calc }}($ ref $)-\sigma_{\text {calc }}$, where $\delta_{\text {exp }}($ ref $)$ denotes the experimental value of the isotropic ${ }^{15} \mathrm{~N}$ NMR chemical shift $\left[\delta_{\exp }(\mathrm{ref})=189.5 \mathrm{ppm}\right]$ for the reference material $\left(\right.$ the $\delta-{ }^{15} \mathrm{~N}$ site in histidine hydrochloride monohydrate) and $\sigma_{\text {calc }}($ ref $)$ denotes the isotropic ${ }^{15} \mathrm{~N}$ NMR shielding value $\left[\sigma_{\text {calc }}(\right.$ ref $\left.)=29.2 \mathrm{ppm}\right]$ for the $\delta{ }^{15} \mathrm{~N}$ site in histidine hydrochloride monohydrate calculated for the known crystal structure of this material ${ }^{73}$ using the same DFT-D methodology as that used to calculate the ${ }^{15} \mathrm{~N}$ shielding values for the alloxazine and isoalloxazine crystal structures.

To determine the relative energies of the crystal structures containing the alloxazine and isoalloxazine tautomers and to assess the energy barriers to convert between these crystal structures, DFT-D calculations were carried out using FHI-aims ${ }^{74}$ (date stamp: 191029) coupled with the Atomic Simulation Environment (ASE) package $^{75}$ and the Catlearn Python package. ${ }^{76}$ Geometry optimization was carried out using the BFGS algorithm implemented in FHI-aims, with a convergence criterion of $0.01 \mathrm{eV} \AA^{-1}$ for atomic forces. Transition states were determined using the machine-learning nudged-elastic band (MLNEB) algorithm provided by Catlearn, ${ }^{52}$ with a convergence criterion of $0.05 \mathrm{eV} \AA^{-1}$ for atomic forces. In both types of calculation, the PBE version ${ }^{64}$ of the general gradient approximation (GGA) was coupled with the Tkatchenko-Scheffler (TS) dispersion correction. ${ }^{65}$ Following convergence of the geometry optimization procedures, single-point energy calculations were carried out using both GGA and hybrid-GGA exchange-correlation functionals, specifically $\mathrm{PBE}^{64}$ and $\mathrm{PBE} 0,{ }^{77}$ coupled with either the TS method $^{65}$ or the many-body dispersion (MBD) method ${ }^{78}$ for dispersion correction. Thus, the complete set of exchange-correlation functionals considered in this work was as follows: PBE-TS, PBEMBD, PBE0-TS, and PBE0-MBD. The electronic structure calculations were carried out with an "intermediate" basis set, and relativistic effects were included via the scaled zeroth order regular approximation. ${ }^{74} \mathrm{~A} \Gamma$-centered $k$-grid was used with a minimum sample spacing of $(0.05 \times 2 \pi) \AA^{-1}$ [Testing with a denser $k$-grid sampling of $(0.04 \times 2 \pi) \AA^{-1}$ gave changes in relative energies less than $1 \mathrm{meV}$.]. The electronic structure self-consistent field (SCF) cycle was considered to be converged when changes in the electron density, the total energy, and the sum of the eigenvalue energies were below $10^{-6} \mathrm{e} \mathrm{a} \mathrm{a}_{0}^{-3}, 10^{-6} \mathrm{eV}$, and $10^{-6} \mathrm{eV}$, respectively.

Additional supporting experimental data and computational data for this article may be accessed at 10.17035/d.2021.0140049329 and 10.17172/NOMAD/2021.10.15-1, respectively.

\section{ASSOCIATED CONTENT}

\section{(s) Supporting Information}

The Supporting Information is available free of charge at https://pubs.acs.org/doi/10.1021/acs.cgd.1c01114.

Crystal structures containing the alloxazine and isoalloxazine tautomers obtained from Rietveld refinement; and crystallographic information for crystal structures (following DFT-D geometry optimization using PBETS) relevant to DFT-D studies of interconversion between the alloxazine and isoalloxazine tautomers, 
specifically crystal structures of alloxazine, isoalloxazine, and the ionic intermediate (ZIP)

Comparison of the crystal structure of alloxazine from Rietveld refinement and the crystal structure obtained following DFT-D geometry optimization of this structure; experimental and calculated solid-state ${ }^{13} \mathrm{C}$ NMR data (PDF)

\section{Accession Codes}

CCDC 2111430 contains the supplementary crystallographic data for this paper. These data can be obtained free of charge via www.ccdc.cam.ac.uk/data_request/cif, or by emailing data_request@ccdc.cam.ac.uk, or by contacting The Cambridge Crystallographic Data Centre, 12 Union Road, Cambridge CB2 1EZ, UK; fax: +44 1223336033.

\section{AUTHOR INFORMATION}

\section{Corresponding Author}

Kenneth D. M. Harris - School of Chemistry, Cardiff

University, Cardiff CF10 3AT, Wales, United Kingdom;

๑ orcid.org/0000-0001-7855-8598; Email: HarrisKDM@

cardiff.ac.uk

\section{Authors}

Christopher J. H. Smalley - School of Chemistry, Cardiff University, Cardiff CF10 3AT, Wales, United Kingdom

Andrew J. Logsdail - Cardiff Catalysis Institute, School of Chemistry, Cardiff University, Cardiff CF10 3AT, Wales, United Kingdom; (1) orcid.org/0000-0002-2277-415X

Colan E. Hughes - School of Chemistry, Cardiff University, Cardiff CF10 3AT, Wales, United Kingdom; 10 orcid.org/ 0000-0003-2374-2763

Dinu Iuga - Department of Physics, University of Warwick, Coventry CV4 7AL, England, United Kingdom

Mark T. Young - School of Biosciences, Cardiff University, Cardiff CF10 3AX, Wales, United Kingdom

Complete contact information is available at: https://pubs.acs.org/10.1021/acs.cgd.1c01114

\section{Notes}

The authors declare no competing financial interest.

\section{ACKNOWLEDGMENTS}

We are grateful to EPSRC (Ph.D. studentship to C.J.H.S.) and Cardiff University for funding. A.J.L. acknowledges funding from the UKRI Future Leaders Fellowship programme (MR/ T018372/1). Computing facilities were provided by ARCCA at Cardiff University, Supercomputing Wales, and through membership of the UK HPC Materials Chemistry Consortium (MCC), which is funded by the EPSRC (EP/R029431). The UK High-Field Solid-State NMR Facility is thanked for the award of spectrometer time. This facility was funded by EPSRC and BBSRC (contract reference PR140003), as well as the University of Warwick, including part funding through Birmingham Science City Advanced Materials Projects 1 and 2 supported by Advantage West Midlands and the European Regional Development Fund.

\section{REFERENCES}

(1) Walsh, C. Flavin coenzymes - at the crossroads of biological redox chemistry. Acc. Chem. Res. 1980, 13, 148-155.

(2) Lin, K.; Gomez-Bombarelli, R.; Beh, E. S.; Tong, L.; Chen, Q.; Valle, A.; Aspuru-Guzik, A.; Aziz, M. J.; Gordon, R. G. A redox flow battery with an alloxazine-based organic electrolyte. Nat. Energy 2016, 1,16102 .

(3) McCusker, L. B. Zeolite crystallography: structure determination in the absence of conventional single-crystal data. Acta Crystallogr., Sect. A: Found. Crystallogr. 1991, 47, 297-343.

(4) Cheetham, A. K.; Wilkinson, A. P. Synchrotron X-ray and neutron diffraction studies in solid-state chemistry. Angew. Chem., Int. Ed. Engl. 1992, 31, 1557-1570.

(5) Lightfoot, P.; Tremayne, M.; Harris, K. D. M.; Bruce, P. G. Determination of a molecular crystal structure by X-ray powder diffraction on a conventional laboratory instrument. J. Chem. Soc., Chem. Commun. 1992, 1012-1013.

(6) Harris, K. D. M.; Tremayne, M.; Lightfoot, P.; Bruce, P. G. Crystal structure determination from powder diffraction data by Monte Carlo methods. J. Am. Chem. Soc. 1994, 116, 3543-3547.

(7) Harris, K. D. M. New opportunities for structure determination of molecular materials directly from powder diffraction data. Cryst. Growth Des. 2003, 3, 887-895.

(8) Tsue, H.; Horiguchi, M.; Tamura, R.; Fujii, K.; Uekusa, H. Crystal structure solution of organic compounds from X-ray powder diffraction data. Yuki Gosei Kagaku Kyokaishi 2007, 65, 1203-1212.

(9) David, W. I. F.; Shankland, K. Structure determination from powder diffraction data. Acta Crystallogr., Sect. A: Found. Crystallogr. 2008, 64, 52-64.

(10) Harris, K. D. M. Powder diffraction crystallography of molecular solids. Top. Curr. Chem. 2012, 315, 133-178.

(11) Martí-Rujas, J. Structural elucidation of microcrystalline MOFs from powder X-ray diffraction. Dalton Trans. 2020, 49, 13897-13916.

(12) Dudenko, D. V.; Williams, P. A.; Hughes, C. E.; Antzutkin, O. N.; Velaga, S. P.; Brown, S. P.; Harris, K. D. M. Exploiting the synergy of powder X-ray diffraction and solid-state NMR spectroscopy in structure determination of organic molecular solids. J. Phys. Chem. C 2013, 117, 12258-12265.

(13) Li, P.; Chu, Y.; Wang, L.; Wenslow, R. M.; Yu, K.; Zhang, H.; Deng, Z. Structure determination of the theophylline-nicotinamide cocrystal: a combined powder XRD, $1 \mathrm{D}$ solid-state NMR, and theoretical calculation study. CrystEngComm 2014, 16, 3141-3147.

(14) Reddy, G. N. M.; Cook, D. S.; Iuga, D.; Walton, R. I.; Marsh, A.; Brown, S. P. An NMR crystallography study of the hemihydrate of 2',3'-O-isopropylidineguanosine. Solid State Nucl. Magn. Reson. 2015, $65,41-48$.

(15) Sardo, M.; Santos, S. M.; Babaryk, A. A.; López, C.; Alkorta, I.; Elguero, J.; Claramunt, R. M.; Mafra, L. Diazole-based powdered cocrystal featuring a helical hydrogen-bonded network: Structure determination from PXRD, solid-state NMR and computer modeling. Solid State Nucl. Magn. Reson. 2015, 65, 49-63.

(16) Watts, A. E.; Maruyoshi, K.; Hughes, C. E.; Brown, S. P.; Harris, K. D. M. Combining the advantages of powder X-ray diffraction and NMR crystallography in structure determination of the pharmaceutical material cimetidine hydrochloride. Cryst. Growth Des. 2016, 16, 1798-1804.

(17) Gumbert, S. D.; Körbitzer, M.; Alig, E.; Schmidt, M. U.; Chierotti, M. R.; Gobetto, R.; Li, X.; van de Streek, J. Crystal structure and tautomerism of Pigment Yellow 138 determined by X-ray powder diffraction and solid-state NMR. Dyes Pigm. 2016, 131, 364-372.

(18) Hughes, C. E.; Reddy, G. N. M.; Masiero, S.; Brown, S. P.; Williams, P. A.; Harris, K. D. M. Determination of a complex crystal structure in the absence of single crystals: analysis of powder X-ray diffraction data, guided by solid-state NMR and periodic DFT calculations, reveals a new 2'-deoxyguanosine structural motif. Chem. Sci. 2017, 8, 3971-3979.

(19) Shirley, R.; Louër, D. New powder indexing programs for any symmetry which combine grid-search with successive dichotomy. Acta Crystallogr. 1978, 34, S382-S382.

(20) Shirley, R. The CRYSFIRE 2002 System for Automatic Powder Indexing: User's Manual; The Lattice Press: Guildford, Surrey, U.K., 2002. 
(21) Le Bail, A.; Duroy, H.; Fourquet, J. L. Ab initio structure determination of $\mathrm{LiSbWO}_{6}$ by X-ray powder diffraction. Mater. Res. Bull. 1988, 23, 447-452.

(22) Larson, A. C.; Von Dreele, R. B. General Structure Analysis System (GSAS). Los Alamos National Laboratory Report, 86-748; 2000.

(23) Harris, K. D. M.; Johnston, R. L.; Hughes, C. E.; Zhou, Z.; Habershon, S.; Turner, G. W.; Williams, P. A.; Kariuki, B. M.; Cheung, E. Y. EAGER - A Computer Program for Direct-Space Structure Solution from Diffraction Data; Cardiff University.

(24) Kariuki, B. M.; Serrano-González, H.; Johnston, R. L.; Harris, K. D. M. The application of a genetic algorithm for solving crystal structures from powder diffraction data. Chem. Phys. Lett. 1997, 280, 189-195.

(25) Harris, K. D. M.; Johnston, R. L.; Habershon, S. Applications of evolutionary computation in structure determination from diffraction data. Struct. Bonding 2004, 110, 55-94.

(26) Harris, K. D. M.; Habershon, S.; Cheung, E. Y.; Johnston, R. L. Developments in genetic algorithm techniques for structure solution from powder diffraction data. Z. Kristallogr. - Cryst. Mater. 2004, 219, 838-846.

(27) Tedesco, E.; Turner, G. W.; Harris, K. D. M.; Johnston, R. L.; Kariuki, B. M. Structure determination of an oligopeptide directly from powder diffraction data. Angew. Chem., Int. Ed. 2000, 39, 44884491.

(28) Williams, P. A.; Hughes, C. E.; Harris, K. D. M. L-Lysine: exploiting powder X-ray diffraction to complete the set of crystal structures of the 20 directly-encoded proteinogenic amino acids. Angew. Chem., Int. Ed. 2015, 54, 3973-3977.

(29) Al Rahal, O.; Hughes, C. E.; Williams, P. A.; Logsdail, A. J.; Diskin-Posner, Y.; Harris, K. D. M. Polymorphism of L-tryptophan. Angew. Chem., Int. Ed. 2019, 58, 18788-18792.

(30) Fujii, K.; Lazuen Garay, A.; Hill, J.; Sbircea, E.; Pan, Z.; Xu, M.; Apperley, D. C.; James, S. L.; Harris, K. D. M. Direct structure elucidation by powder X-ray diffraction of a metal-organic framework material prepared by solvent-free grinding. Chem. Commun. 2010, 46, $7572-7574$.

(31) Brekalo, I.; Yuan, W.; Mottillo, C.; Lu, Y.; Zhang, Y.; Casaban, J.; Holman, K. T.; James, S. L.; Duarte, F.; Williams, P. A.; Harris, K. D. M.; Frišcić, T. Manometric real-time studies of the mechanochemical synthesis of zeolitic imidazolate frameworks. Chem. Sci. 2020, 11, 2141-2147.

(32) Guo, F.; Martí-Rujas, J.; Pan, Z.; Hughes, C. E.; Harris, K. D. M. Direct structural understanding of a topochemical solid state photopolymerization reaction. J. Phys. Chem. C 2008, 112, 1979319796.

(33) Martí-Rujas, J.; Meazza, L.; Lim, G. K.; Terraneo, G.; Pilati, T.; Harris, K. D. M.; Metrangolo, P.; Resnati, G. An adaptable and dynamically porous organic salt traps unique tetrahalide dianions. Angew. Chem., Int. Ed. 2013, 52, 13444-13448.

(34) Tedesco, E.; Della Sala, F.; Favaretto, L.; Barbarella, G.; AlbesaJové, D.; Pisignano, D.; Gigli, G.; Cingolani, R.; Harris, K. D. M. Solid-state supramolecular organization, established directly from powder diffraction data, and photoluminescence efficiency of rigidcore oligothiophene-S,S-dioxides. J. Am. Chem. Soc. 2003, 125, 12277-12283.

(35) Ma, X.; Lim, G. K.; Harris, K. D. M.; Apperley, D. C.; Horton, P. N.; Hursthouse, M. B.; James, S. L. Efficient, scalable and solventfree mechanochemical synthesis of the OLED material $\mathrm{Alq}_{3}(\mathrm{q}=8$ hydroxyquinolinate). Cryst. Growth Des. 2012, 12, 5869-5872.

(36) Albesa-Jové, D.; Kariuki, B. M.; Kitchin, S. J.; Grice, L.; Cheung, E. Y.; Harris, K. D. M. Challenges in direct-space structure determination from powder diffraction data: a molecular material with four independent molecules in the asymmetric unit. ChemPhysChem 2004, 5, 414-418.

(37) Zhou, Y.; Guo, F.; Hughes, C. E.; Browne, D. L.; Peskett, T. R.; Harris, K. D. M. Discovery of new meta-stable polymorphs in a family of urea co-crystals by solid-state mechanochemistry. Cryst. Growth Des. 2015, 15, 2901-2907.
(38) Williams, P. A.; Hughes, C. E.; Lim, G. K.; Kariuki, B. M.; Harris, K. D. M. Discovery of a new system exhibiting abundant polymorphism: $m$-aminobenzoic acid. Cryst. Growth Des. 2012, 12, 3104-3113.

(39) Bruno, I. J.; Cole, J. C.; Kessler, M.; Luo, J.; Motherwell, W. D. S.; Purkis, L. H.; Smith, B. R.; Taylor, R.; Cooper, R. I.; Harris, S. E.; Orpen, A. G. Retrieval of crystallographically-derived molecular geometry information. J. Chem. Inf. Comput. Sci. 2004, 44, 21332144

(40) Allen, F. H.; Kennard, O.; Watson, D. G.; Brammer, L.; Orpen, A. G.; Taylor, R. Tables of bond lengths determined by X-ray and neutron-diffraction. J. Chem. Soc., Perkin Trans. 2 1987, S1-S19.

(41) Rietveld, H. M. A profile refinement method for nuclear and magnetic structures. J. Appl. Crystallogr. 1969, 2, 65-71.

(42) An independent assessment of the extent of preferred orientation in the powder sample was established by recording powder XRD data using a two-dimensional detector, which showed essentially uniform intensity of the Debye-Scherrer rings.

(43) Desiraju, G. R.; Steiner, T. The Weak Hydrogen Bond; IUCr and Oxford University Press: 1999; DOI: 10.1093/acprof:oso/ 9780198509707.001.0001.

(44) Steiner, T. Unrolling the hydrogen bond properties of $\mathrm{C}-\mathrm{H} \cdots$ O interactions. Chem. Commun. 1997, 727-734.

(45) Steiner, T.; Desiraju, G. R. Distinction between the weak hydrogen bond and the van der Waals interaction. Chem. Commun. 1998, 891-892.

(46) Etter, M. C.; Macdonald, J. C.; Bernstein, J. Graph-set analysis of hydrogen bond patterns in organic crystals. Acta Crystallogr., Sect. B: Struct. Sci. 1990, 46, 256-262.

(47) Kumar, V.; Woode, K. A.; Bryan, R. F.; Averill, B. A. Evidence for a competing condensation reaction in the alloxan synthesis of flavins: synthesis and crystal and molecular structures of 7-chloro-8methylalloxazine and 7,10-dimethyl-8-[(2-hydroxyethyl)thio]isoalloxazine. J. Am. Chem. Soc. 1986, 108, 490-496.

(48) Csoregh, I.; Kierkegaard, P.; Koziol, J.; Muller, F. The molecular and crystal structures of 9-methyl- and 1,3,8,9-tetramethylalloxazines. Acta Chem. Scand. 1987, 41B, 383-390.

(49) Sikorska, E.; Khmelinskii, I. V.; Kubicki, M.; Prukała, W.; Nowacka, G.; Siemiarczuk, A.; Koput, J.; Ferreira, L. F. V.; Sikorski, M. Hydrogen-bonded complexes of lumichrome. J. Phys. Chem. A 2005, 109, 1785-1794.

(50) Sikorski, M.; Kubicki, M. CSD Communication (Private Communication); 2018; (Refcode: AGEPEK).

(51) To ensure that the DFT-D calculations for the crystal structures of the two tautomers were based on the same unit cell, the unit cell parameters were taken as the average of the unit cell parameters for the two structures obtained in the Rietveld refinements. The differences between these averaged unit cell parameters and the refined unit cell parameters from the Rietveld refinements are less than the estimated standard deviations in the refined values, and the differences are therefore not significant with respect to the "experimental errors" in the refined values.

(52) Garrido Torres, J. A.; Jennings, P. C.; Hansen, M. H.; Boes, J. R.; Bligaard, T. Low-scaling algorithm for nudged elastic band calculations using a surrogate machine learning model. Phys. Rev. Lett. 2019, 122, 156001 .

(53) Meier, B. H.; Graf, F.; Ernst, R. R. Structure and dynamics of intramolecular hydrogen-bonds in carboxylic-acid dimers - a solidstate NMR study. J. Chem. Phys. 1982, 76, 767-774.

(54) Nagaoka, S.; Terao, T.; Imashiro, F.; Saika, A.; Hirota, N.; Hayashi, S. An NMR relaxation study on the proton-transfer in the hydrogen-bonded carboxylic-acid dimers. J. Chem. Phys. 1983, 79, 4694-4703.

(55) Aliev, A. E.; Harris, K. D. M. Probing hydrogen bonding in solids using solid state NMR spectroscopy. Struct. Bonding 2004, 108, $1-53$.

(56) For the sequential mechanism, the two transition states and the ionic intermediate are also stabilized relative to the alloxazine and isoalloxazine crystal structures as a result of the many-body dispersion 
corrections but only by maximum values of $2.3 \mathrm{~kJ} \mathrm{~mol}^{-1}$ relative to alloxazine and $1.3 \mathrm{~kJ} \mathrm{~mol}^{-1}$ relative to isoalloxazine.

(57) Shtukenberg, A. G.; Zhu, Q.; Carter, D. J.; Vogt, L.; Hoja, J.; Schneider, E.; Song, H.; Pokroy, B.; Polishchuk, I.; Tkatchenko, A.; Oganov, A. R.; Rohl, A. L.; Tuckerman, M. E.; Kahr, B. Powder diffraction and crystal structure prediction identify four new coumarin polymorphs. Chem. Sci. 2017, 8, 4926-4940.

(58) Hoja, J.; Ko, H. Y.; Neumann, M. A.; Car, R.; DiStasio, R. A.; Tkatchenko, A. Reliable and practical computational description of molecular crystal polymorphs. Science Advances 2019, 5, eaau3338.

(59) Fung, B. M.; Khitrin, A. K.; Ermolaev, K. An improved broadband decoupling sequence for liquid crystals and solids. J. Magn. Reson. 2000, 142, 97-101.

(60) Taylor, R. E. C-13 CP/MAS: Application to glycine. Concepts Magn. Reson. 2004, 22A, 79-89.

(61) Bertani, P.; Raya, J.; Bechinger, B. ${ }^{15} \mathrm{~N}$ chemical shift referencing in solid state NMR. Solid State Nucl. Magn. Reson. 2014, 61-62, 15-18.

(62) Clark, S. J.; Segall, M. D.; Pickard, C. J.; Hasnip, P. J.; Probert, M. J.; Refson, K.; Payne, M. C. First principles methods using CASTEP. Z. Kristallogr. - Cryst. Mater. 2005, 220, 567-570.

(63) Vanderbilt, D. Soft self-consistent pseudopotentials in a generalized eigenvalue formalism. Phys. Rev. B: Condens. Matter Mater. Phys. 1990, 41, 7892-7895.

(64) Perdew, J. P.; Burke, K.; Ernzerhof, M. Generalized gradient approximation made simple. Phys. Rev. Lett. 1996, 77, 3865-3868.

(65) Tkatchenko, A.; Scheffler, M. Accurate molecular Van Der Waals interactions from ground-state electron density and free-atom reference data. Phys. Rev. Lett. 2009, 102, 073005.

(66) Monkhorst, H. J.; Pack, J. D. Special points for Brillouin-zone integrations. Phys. Rev. B 1976, 13, 5188-5192.

(67) Pickard, C. J.; Mauri, F. All-electron magnetic response with pseudopotentials: NMR chemical shifts. Phys. Rev. B: Condens. Matter Mater. Phys. 2001, 63, 245101.

(68) Yates, J. R.; Pickard, C. J.; Mauri, F. Calculation of NMR chemical shifts for extended systems using ultrasoft pseudopotentials. Phys. Rev. B: Condens. Matter Mater. Phys. 2007, 76, 024401.

(69) Harris, R. K.; Hodgkinson, P.; Pickard, C. J.; Yates, J. R.; Zorin, V. Chemical shift computations on a crystallographic basis: some reflections and comments. Magn. Reson. Chem. 2007, 45, S174-S186.

(70) Charpentier, T. The PAW/GIPAW approach for computing NMR parameters: a new dimension added to NMR study of solids. Solid State Nucl. Magn. Reson. 2011, 40, 1-20.

(71) Bonhomme, C.; Gervais, C.; Babonneau, F.; Coelho, C.; Pourpoint, F.; Azaïs, T.; Ashbrook, S. E.; Griffin, J. M.; Yates, J. R.; Mauri, F.; Pickard, C. J. First-principles calculation of NMR parameters using the gauge including projector augmented wave method: a chemist's point of view. Chem. Rev. 2012, 112, 5733-5779.

(72) Ashbrook, S. E.; McKay, D. Combining solid-state NMR spectroscopy with first-principles calculations - a guide to NMR crystallography. Chem. Commun. 2016, 52, 7186-7204.

(73) Fuess, H.; Hohlwein, D.; Mason, S. A. Neutron diffraction study of L-histidine hydrochloride monohydrate. Acta Crystallogr., Sect. B: Struct. Crystallogr. Cryst. Chem. 1977, 33, 654-659.

(74) Blum, V.; Gehrke, R.; Hanke, F.; Havu, P.; Havu, V.; Ren, X.; Reuter, K.; Scheffler, M. Comput. Phys. Commun. 2009, 180, 21752196.

(75) Hjorth Larsen, A.; et al. The atomic simulation environment a Python library for working with atoms. J. Phys.: Condens. Matter 2017, 29, 273002.

(76) Hansen, M. H. An Atomistic Machine Learning Package for Surface Science and Catalysis. https://arxiv.org/abs/1904.00904 (accessed 2021-11-07).

(77) Adamo, C.; Barone, V. Toward reliable density functional methods without adjustable parameters: the PBE0 model. J. Chem. Phys. 1999, 110, 6158-6170.

(78) Ambrosetti, A.; Reilly, A. M.; DiStasio, R. A.; Tkatchenko, A. Long-range correlation energy calculated from coupled atomic response functions. J. Chem. Phys. 2014, 140, 18A508.

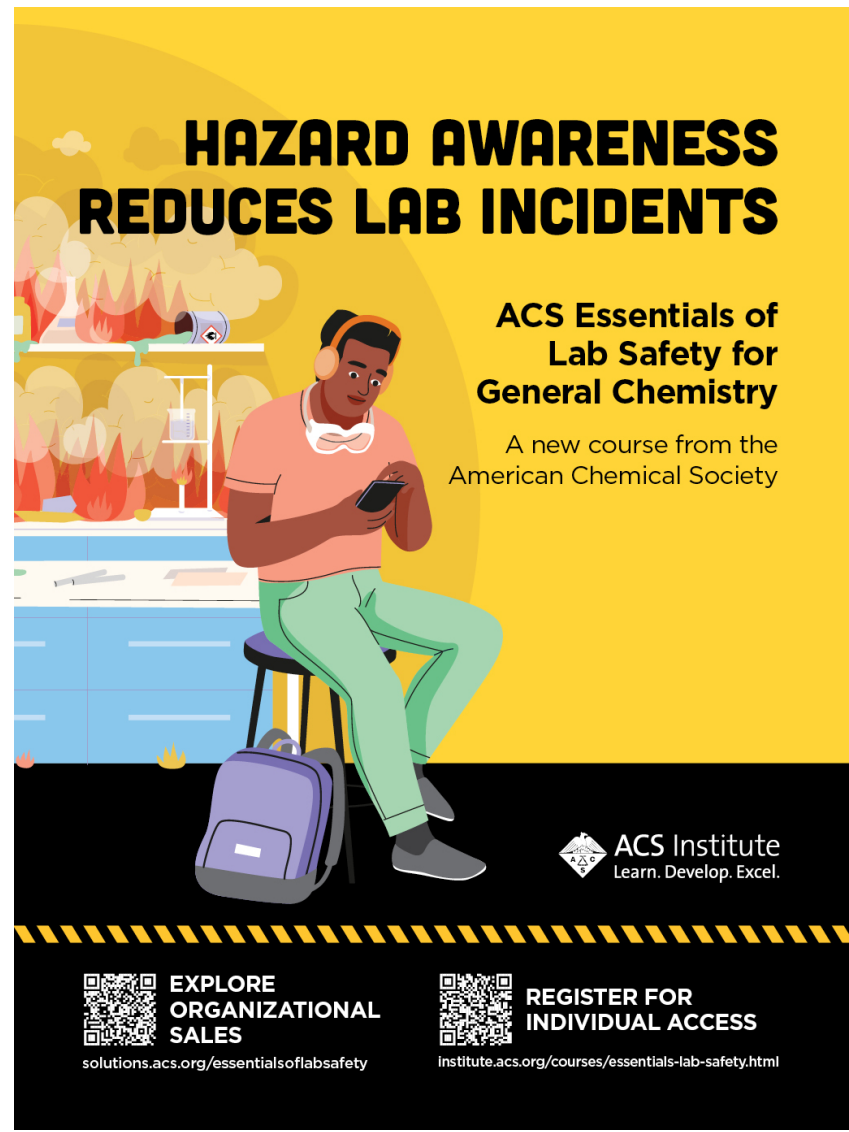

